\title{
Influence of family resources on secondhand smoking in pregnant women: a cross-sectional study in the border and minority urban areas of Northwest China
}

\author{
Jiangyun Chen ${ }^{1}$, Xinhui Li2 ${ }^{2^{*}}$ and Pengqian Fang ${ }^{3,4^{*}}$ (D
}

\begin{abstract}
Background: Pregnant women's exposure to secondhand smoke is a very serious health issue in China. The purpose of our research is to identify factors that predict the probability of exposure to secondhand smoke among pregnant women from the perspective of a family-based open system.

Methods: From September 2014 to August 2015, Urumqi City, Shihezi City, and Shawan County-level City were sampled according to population characteristics. A revised structured questionnaire based on family resources was adapted for use in this study. Questionnaires were collected via convenience sampling at the hospitals with the largest number of local antenatal clients. A total of 1249 pregnant women of age 18-51 years were investigated. Descriptive statistics were calculated to characterize the participants and study variables. Binary logistic regression was performed to assess the impact of family resources corresponding variables on the likelihood that participants would be exposed to SHS. Both unadjusted and adjusted odds ratios (OR/AOR) [with 95\% confidence intervals (CI)] were reported.

Results: The secondhand smoke exposure rate found in this study was 54.6\%. Having good knowledge of the dangers of secondhand smoke had no effect on reducing the prevalence of exposure $(P>0.05)$. Even pregnant women whose husbands who did not use tobacco or never smoked nearby had a risk of exposure to secondhand smoke [adjusted odds ratio (AOR) 1.568,95\% Cl 1.205-2.041] when the data were adjusted for age, gravidity, gestational weeks, knowledge of the dangers of secondhand smoke, location, and work status. Home smoking bans were confirmed to be an important protective factor (AOR 1.710, 95\% Cl 1.549-1.918); however, only one-third (33.5\%) of participants reported having a smoking ban at home. Religion (mainly Islam), as a special external family resource, was a protective factor that reduced secondhand smoke exposure in pregnant women (AOR 0.399, 95\% Cl 0.312-0.510).

\footnotetext{
*Correspondence: lixinhui@shzu.edu.cn; pfang@mails.tjmu.edu.cn

${ }^{2}$ School of Medicine, Shihezi University, No.221 Beisi Road, Shihezi, Xinjiang

832002, Uygur Autonomous Region, China

${ }^{3}$ Academy of Health Policy and Management, Huazhong University of

Science and Technology (Think tank), No.13 Hangkong Road, Qiaokou District, Wuhan 430030, Hubei, China

Full list of author information is available at the end of the article
}

C C The Author(s). 2020 Open Access This article is licensed under a Creative Commons Attribution 4.0 International License, which permits use, sharing, adaptation, distribution and reproduction in any medium or format, as long as you give appropriate credit to the original author(s) and the source, provide a link to the Creative Commons licence, and indicate if changes were made. The images or other third party material in this article are included in the article's Creative Commons licence, unless indicated otherwise in a credit line to the material. If material is not included in the article's Creative Commons licence and your intended use is not permitted by statutory regulation or exceeds the permitted use, you will need to obtain permission directly from the copyright holder. To view a copy of this licence, visit http://creativecommons.org/licenses/by/4.0/ The Creative Commons Public Domain Dedication waiver (http://creativecommons.org/publicdomain/zero/1.0/) applies to the data made available in this article, unless otherwise stated in a credit line to the data. 
(Continued from previous page)

Conclusions: The effect of family resources on tobacco control should be considered in the development of effective and enduring strategies for indoor smoking bans and smoking cessation.

Keywords: Pregnant women, Secondhand smoke, Family resources, Home smoking ban, Religion

\section{Background}

China has the largest number of tobacco consumers in the world, and secondhand smoke (SHS) exposure remains a serious issue. In China, 740 million people are routinely exposed to SHS and 100 hundred deaths related every year [1]. According to the 2018 China Adult Tobacco Survey (CATS), the current prevalence of smoking for females $(2.1 \%)$ is far lower than that for males (50.5\%) [2]. According to the 2010 Global Adult Tobacco Survey (GATS), the percentages of SHS exposure among women aged 15-49years in China were $65.1 \%$ at home and $52.6 \%$ at work [3]. Apparently, nonsmoking women of reproductive age are one of the main groups exposed to SHS in China.

The harmful effects of SHS have been well documented in studies conducted in China on pregnant women themselves (such as lung cancer, ischaemic heart diseases, stroke, cervical neoplasia, chronic obstructive pulmonary, and insufficient sleep duration) [4-7], and their foetuses or offspring (such low birthweight, congenital malformations, spontaneous abortion, orofacial clefts, and decreased lung function) [8-12].

Currently, the effect of a government anti-smoking policy in China is obvious in administrative office buildings, schools, hospitals, airports, and trains; however, there is no related regulation prohibiting smoking at home. Recent evidence has shown that the use of tobacco in the home environment leads to poor indoor air quality (IAQ) and causes serious SHS, with median PM2.5 concentrations in smoking-permitted homes ten times higher than in smoke-free homes [13]. Thus far, home smoking bans have not been widely adopted by Chinese families (only 20\%) [1], and $44.9 \%$ of adults reported that someone in their home smoked [2].

A family is a system because it is composed of interrelated parts. The components of the family stem are the individual family members. The environment of the family system is the larger society, the culture in which it is located [14]. General systems theory provides the basis for the conception of the family system $[15,16]$. In a family-based open system, pregnant women's exposure to SHS is the result of a combination of internal and external family resources, which should be explored in terms of local unique social, cultural and religious backgrounds, the smoking behaviours of major family members, etc. It was reported that $71.4 \%$ of husbands who smoke did not smoke near their wives during pregnancy [17], and the prevalence of SHS among women decreased from 55.9 to $41.9 \%$ after pregnancy [18].

The standardised smoking prevalence varied in different provinces of China, the smoking prevalence in Xinjiang Uyghur Autonomous Region has consistently been below the national average of China, from $15.4 \%$ in 2003 to $16.2 \%$ in 2013 and $22.7 \%$ in 2017 [19, 20]. Lower rates of smoking than the national average of China might due to the majority of the local residents are Muslims. Results of previous studies have suggested that religious activities may have a protective role against cigarette smoking among Muslims [21]. Young adults who attend religious services have lower rates of current and subsequent cigarette smoking [22]. Although lower than the national level, the smoking rate in Xinjiang is still on the rise. The risks of secondhand smoking prevalence may be affected by these trends, and the issue of passive smoking should cause more attention.

There are few investigations on such special region and the autonomous province multi-ethnic people's passive smoking status and analyse the influencing factors. This study is the first to our knowledge to focus on secondhand smoke among pregnant women from the perspective of a family-based open system in an ethnically diverse area of China. The objective of this study of nonsmoking pregnant women in the Xinjiang Uyghur Autonomous Region was to identify SHS exposureassociated factors considering family resources, including social, cultural, religious, economic and medical aspects [23].

\section{Subjects and methods Sample strategy}

From September 2014 to August 2015, a hospital-based cross-sectional study was conducted in Urumqi City, Shihezi City, and Shawan County-level City in the Xinjiang Uygur Autonomous Region. These cities were selected using typical sampling. In terms of city size (small, medium and large cities, which have populations of $>0.2 \sim 0.5$ million, $>0.5 \sim 1$ million, $>1 \sim 5$ million, respectively), Urumqi City is the only large city in Xinjiang Uygur Autonomous Region and is one of the cities with the highest proportion of Uyghurs (30.83\%), Shihezi City is a medium city and has the highest proportion of Han (94.84\%), and Shawan County-level City 
is a small city and has the highest proportion of Kazakhs (52.49\%). Questionnaires were collected via convenience sampling at the hospitals with the largest number of antenatal clients (Xinjiang Autonomous Region People's Hospital, Shihezi City People's Hospital, and Shawan County Maternal and Child Health Hospital). The inclusion criteria for this study were as follows: (a) an intrauterine pregnancy, (b) the provision of informed consent, (c) local residency, defined as having lived in the area for a cumulative total of 6 months in the last year. The exclusion criteria were (a) mental incompetence and (b) inability to complete the survey for other reasons.

As most pregnant women had fetal heart monitoring every week, medical personnel helped to recruit each eligible target population after finished a prenatal examination. Then eligible participants were informed of the study purpose by investigator and requested to participate in the investigation. After obtaining approval, investigations were conducted in the antenatal clinics of the hospitals. The questionnaire was completed by the participants themselves. Investigators participated in the survey throughout the process and recovered all questionnaires. Uighur/Kazakh nurses were present to help minority participants who had difficulty reading Chinese.

\section{Sample size}

To ensure that our sample of non-smoking pregnant women was of sufficient size, we calculated the power using the maternal passive smoking rate during pregnancy $(P)$ in China (which ranged from 26.6 to $45.3 \%$ in recent years) [23-25]. Specifically, using the survey sample size calculation formula $\left(n=t_{\alpha}{ }^{2} P Q / d^{2}\right)$ with a $P=$
$26.6 \%$, an allowable error $(d)$ of $0.1 P$ and a predetermined $\alpha$ of 0.05 , the required sample size of pregnant women was 1104. Of 1395 eligible pregnant women, 1327 (95.1\%) consented to participate. A total of 1327 questionnaires were distributed and recovered, with a response rate of $100 \%$. Seventy-eight questionnaires were removed from the study because of incomplete answers or illogical errors. A total of 1249 usable questionnaires were collected for an efficiency of $94.1 \%$.

\section{Questionnaire}

Family resources are defined as the material and spiritual support needed to maintain basic family functions and respond to stressful events and crisis situations. The adequacy of family resources is directly related to the ability of family members to adapt to stress and crisis. Family resources can be divided into domestic resources and extra-family resources (Table 1 ), which include social, cultural, religious, economic and medical aspects $[23,26]$. According to family resources and corresponding variables, a revised structured questionnaire with a Kaiser-Meyer-Olkin value of 0.816 was adapted for use in this study (Supplementary questionnaire file 1).

The questionnaire consisted of two parts: (a) The first part focused on demographic characteristics such as age, location, nationality, religion, gravidity, gestational weeks, education, work status and income, whether regular prenatal checkups took place, and residence or facility changes; (b) The second part focused on passive smoking status (exposure to environmental tobacco smoke at least 1 day per week, regardless of exposure time) and related characteristics, such as home smoking

Table 1 Family resources and corresponding variables

\begin{tabular}{ll}
\hline Dimensions & Variables \\
\hline Internal family resources & Annual income \\
Financial support & Home smoking ban, Husband tobacco use, Household tobacco use \\
Advocacy/Maintenance & Regular prenatal checkup \\
Medical management & Marital relationships \\
Love support & Age, Gravidity times, Gestational weeks, Knowledge of secondhand smoke harm \\
Information and knowledge & Residence or facility changes \\
Structural support & \\
External family resources & Community tobacco control education \\
Social resources & Nationality \\
Cultural resources & Religion \\
Religious resources & Insurance \\
Economic resources & Education \\
Educational resources & Location, Work status \\
Environmental resources & Have medical institutions in the living community \\
Medical resources & \\
\hline
\end{tabular}


bans, husband's tobacco use, household tobacco use, community tobacco control education, etc.

In addition, a marital relationships scale and a secondhand smoke harm knowledge scale were provided. After reviewing and revising the marital satisfaction scale [27], we measured marital relationships with 20 questions about self-perceptions of the partner and marital life that were answered via a four-point Likert scale. The Cronbach's alpha of this scale was 0.878 . The score is between 20 and 80 points. A higher score means that respondents tend to be satisfied with the marriage. Six items answered using a four-point Likert were used to measure the knowledge level of secondhand smoke harm by referencing SHS health hazards from the website of Chinese Centre for Control and Prevention (CDC) [28], and the Cronbach's alpha was 0.826 . The score is between 6 and 24 points. A higher score indicates better knowledge of the harms of secondhand smoke.

\section{Definition of SHS}

According to the definition in the Global Adult Tobacco Survey 2010, secondhand smoke exposure (SHS) is defined as the exposure of a non-smoker to environmental tobacco smoke at least 1 day per week, and the rate of secondhand smoke exposure is the percentage of nonsmokers who are exposed to secondhand smoke [29].

\section{Data analysis}

The Epidata 3.1 software was used to create a database and enter data. SPSS statistical software version 20.0 for Windows was used for all data analyses. Descriptive statistics were calculated to characterize the participants and study variables. The chi-square test was used to compare the distribution of the SHS exposure rate between different social demographic characteristics groups. The Spearman correlation test was used to assess the correlations among variables. We used selfrated SHS exposure as the binary dependent variable. Ten independent variables were significant at the $<0.10$ level (home smoking bans, husband's tobacco use, household tobacco use, age, gravidity, gestational weeks, knowledge of the dangers of secondhand smoke, religion, location, work status) and were selected for inclusion in the model. Using a criterion of a $p$-value under 0.05 , binary logistic regression was performed to assess the impact of these variables on the likelihood that participants would be exposed to SHS. Both unadjusted and adjusted odds ratios (OR/AOR) [with 95\% confidence intervals $(\mathrm{CI})]$ were reported.

\section{Results}

\section{Characteristics of participants}

Among the sample of 1249, 32.1\% were from the Urumqi, 23.8\% from Shihezi and 12.3\% from Shawan.
The mean (SD) reported age was 29.1 years (4.6). Onehalf $(52.0 \%)$ of the participants were Han, and onequarter $(25.5 \%)$ of them were Uygur, followed by Kazak (12.9\%). Less than half (46.0\%) of the participants reported having religious beliefs, mainly Islam $(n=556$, 96.9\%). Approximately half (54.2\%) of the participants were primigravida, and most (92.2\%) of the participants were more than 12 weeks pregnant. The majority $(66.5 \%)$ of the participants reported having completed high school, and three-quarter $(75.5 \%)$ of the participants reported working during their pregnancy. More than half $(53.5 \%)$ of the participants reported a household per capita annual income of USD $5421 \sim 12,649$. Only a few (3.4\%) of the participants had no health insurance. Almost all (99.6\%) the participants had medical institutions in the community where they lived. The marital relationship scale scores were $(60.6 \pm 5.7)$, and the secondhand smoke harm knowledge scale score were $(21.7 \pm 2.7)$, which were both in the upper middle level.

\section{SHS prevalence rate and distribution}

The overall rate of secondhand smoke exposure among the pregnant women in this investigation was $54.6 \%$ (682/1249). Participants having home smoking ban and participants with religious beliefs reported lower rate of SHS prevalence for 47.6 and $43.3 \%$, respectively. The prevalence of SHS was higher among participants whose husbands smoked. The SHS prevalence rate of the husband smoking nearby was as high as $92.8 \%$, and even if the husband was not smoking nearby, the SHS prevalence rate also reached $57.2 \%$.

The chi-square test was used to compare the distributions of SHS exposure rate according to family resource characteristics. The results showed statistically significant differences in the distribution of the secondhand smoke exposure rate for the following variables: home smoking bans, husband's tobacco use, age, gravidity, gestational weeks, knowledge of the harms of secondhand smoke, household tobacco use, nationality, religion, location, and work status $(P<0.1)$ (Table 2, Table 3$)$.

\section{Influencing factors of SHS}

To investigate the correlations among the eleven variables identified in the bivariate analysis, Spearman's rho correlation coefficient was calculated (Table 4). The results showed that there might be a positive correlation between nationality and religion, with $r=0.806(P<$ $0.001)$. In this study, there was an overlap in religions among different nationalities, and Islam is also believed by Han, Uyghurs, Kazaks and others. To avoid the interference of confounding factors, when there was a collinearity between nationality and religion, religion was selected for inclusion in the model development. 
Table 2 Comparison of secondhand smoke exposure rate among different internal family resources $(n=1249)$

\begin{tabular}{|c|c|c|c|c|c|c|}
\hline $\begin{array}{l}\text { Internal family resources } \\
\text { Dimensions }\end{array}$ & Variables & $\begin{array}{l}\text { Overall } \\
N=1249(\%), \\
\text { mean (SD) }\end{array}$ & $\begin{array}{l}\text { Secondhand smokers } \\
N=682(\%)\end{array}$ & $\begin{array}{l}\text { Rate of secondhand } \\
\text { smoke exposure (\%) }\end{array}$ & $x^{2}$ & $\begin{array}{l}P \\
\text { value }\end{array}$ \\
\hline \multirow[t]{4}{*}{ Financial support } & Annual income (USD) & & & & 0.602 & 0.740 \\
\hline & $<5421$ & $226(18.1)$ & $122(17.9)$ & 54.0 & & \\
\hline & $5421 \sim 12,649$ & $668(53.5)$ & $360(52.8)$ & 53.9 & & \\
\hline & $>12,649$ & $355(28.4)$ & $200(29.3)$ & 56.3 & & \\
\hline \multirow[t]{11}{*}{ Advocacy/Maintenance } & Home smoking ban & & & & 12.405 & $<0.001$ \\
\hline & Yes & $418(33.5)$ & $199(29.2)$ & 47.6 & & \\
\hline & No & $831(66.5)$ & $483(70.8)$ & 58.1 & & \\
\hline & Husband tobacco use & & & & 117.199 & $<0.001$ \\
\hline & No tobacco use & $702(56.2)$ & $315(46.2)$ & 44.9 & & \\
\hline & Smoke but not nearby & 395 (31.6) & $226(33.1)$ & 57.2 & & \\
\hline & Smoke nearby & $152(12.2)$ & $141(20.7)$ & 92.8 & & \\
\hline & $\begin{array}{l}\text { Household tobacco use } \\
\text { (except husband) }\end{array}$ & & & & 27.252 & $<0.001$ \\
\hline & No tobacco use & 791 (63.3) & $403(59.0)$ & 50.9 & & \\
\hline & Smoke but not nearby & $348(27.9)$ & $194(28.5)$ & 55.9 & & \\
\hline & Smoke nearby & $110(8.8)$ & $85(12.5)$ & 77.3 & & \\
\hline \multirow[t]{3}{*}{ Medical management } & Regular prenatal checkup & & & & 0.487 & 0.485 \\
\hline & Yes & $1202(96.2)$ & $654(95.9)$ & 54.4 & & \\
\hline & No & $47(3.8)$ & $28(4.1)$ & 59.6 & & \\
\hline \multirow[t]{3}{*}{ Love support } & Marital relationships & & & & 1.751 & 0.186 \\
\hline & $\leq 61$ & $633(50.7)$ & $334(53.2)$ & 52.8 & & \\
\hline & $>61$ & $616(49.3)$ & $348(46.8)$ & 56.5 & & \\
\hline \multirow[t]{13}{*}{ Information and knowledge } & Age & $29.1 \pm 4.6$ & & & 10.461 & 0.001 \\
\hline & $\geq 29$ & $642(51.4)$ & $379(55.6)$ & 59.0 & & \\
\hline & $<29$ & $607(48.6)$ & $303(44.4)$ & 49.9 & & \\
\hline & Gravidity times & & & & 3.059 & 0.080 \\
\hline & 1 & $677(54.2)$ & $385(56.5)$ & 56.9 & & \\
\hline & $\geq 2$ & $572(45.8)$ & $297(43.5)$ & 51.9 & & \\
\hline & Gestational weeks & & & & 5.944 & 0.051 \\
\hline & $\leq 12$ & $98(7.8)$ & $53(7.8)$ & 54.1 & & \\
\hline & $13 \sim 28$ & $432(34.6)$ & $256(37.5)$ & 59.3 & & \\
\hline & $>28$ & $719(57.6)$ & $373(54.7)$ & 51.9 & & \\
\hline & $\begin{array}{l}\text { Knowledge of secondhand } \\
\text { smoke harm }\end{array}$ & & & & 3.874 & 0.053 \\
\hline & $\leq 22$ & $591(47.3)$ & $340(50.1)$ & 57.5 & & \\
\hline & $>22$ & $658(52.7)$ & $342(49.9)$ & 52.0 & & \\
\hline \multirow[t]{3}{*}{ Structural support } & Residence or facility changes & & & & 0.809 & 0.368 \\
\hline & Yes & $58(4.6)$ & $35(5.1)$ & 60.3 & & \\
\hline & No & $1191(95.4)$ & $647(94.9)$ & 54.3 & & \\
\hline
\end{tabular}

Binary logistic regression was performed to assess the impact of ten significant independent variables on the likelihood that participants would be exposed to SHS. The full model was statistically significant, $\chi^{2}=246.32$,
$P<0.001$. Only five of the variables made a unique statistically significant contribution to the model (Table 5). The strongest predictor of exposure to SHS was having a husband who smoked nearby (versus a husband who 
Table 3 Comparison of secondhand smoke exposure rate among different external family resources $(n=1249)$

\begin{tabular}{|c|c|c|c|c|c|c|}
\hline $\begin{array}{l}\text { External family } \\
\text { resources Dimensions }\end{array}$ & Variables & $\begin{array}{l}\text { Overall } N=1249(\%), \\
\text { mean (SD) }\end{array}$ & $\begin{array}{l}\text { Secondhand } \\
\text { smokers } N=682(\%)\end{array}$ & $\begin{array}{l}\text { Rate of secondhand } \\
\text { smoke exposure (\%) }\end{array}$ & $x^{2}$ & $\begin{array}{l}P \\
\text { value } \\
\end{array}$ \\
\hline \multirow[t]{3}{*}{ Social resources } & $\begin{array}{l}\text { Community tobacco } \\
\text { control education }\end{array}$ & & & & 0.014 & 0.906 \\
\hline & Yes & $868(69.5)$ & $473(69.4)$ & 54.5 & & \\
\hline & No & $381(30.5)$ & $209(30.6)$ & 54.9 & & \\
\hline \multirow[t]{6}{*}{ Cultural resources } & Nationality & & & & 54.080 & $<0.001$ \\
\hline & Han & $650(52.0)$ & $417(61.1)$ & 64.2 & & \\
\hline & Uygur & $319(25.5)$ & $137(20.1)$ & 42.9 & & \\
\hline & Kazak & $161(12.9)$ & $70(10.3)$ & 43.5 & & \\
\hline & Hui & $103(8.3)$ & $47(6.9)$ & 45.6 & & \\
\hline & others & $16(1.3)$ & $11(1.6)$ & 68.8 & & \\
\hline \multirow[t]{3}{*}{ Religious resources } & Religion & & & & 53.978 & $<0.001$ \\
\hline & Yes & $574(46.0)$ & $249(36.5)$ & 43.3 & & \\
\hline & No & $675(54.0)$ & $433(63.5)$ & 64.1 & & \\
\hline \multirow[t]{3}{*}{ Economic resources } & Insurance & & & & 0.225 & 0.636 \\
\hline & Yes & 1206 (96.6) & $657(96.3)$ & 54.5 & & \\
\hline & No & $43(3.4)$ & $25(3.7)$ & 58.1 & & \\
\hline \multirow[t]{3}{*}{ Educational resources } & Education & & & & 2.370 & 0.124 \\
\hline & High school or less & $419(33.5)$ & $216(31.7)$ & 51.6 & & \\
\hline & Above high school & $830(66.5)$ & $466(68.3)$ & 56.1 & & \\
\hline \multirow[t]{7}{*}{ Environmental resources } & Location & & & & 13.302 & 0.001 \\
\hline & Urumqi & $622(49.8)$ & $321(47.1)$ & 51.6 & & \\
\hline & Shihezi & $382(30.6)$ & $238(34.9)$ & 62.3 & & \\
\hline & Shawan & $245(19.6)$ & $123(18.0)$ & 50.2 & & \\
\hline & Work during pregnancy & & & & 4.196 & 0.041 \\
\hline & Yes & $946(75.7)$ & $532(78.0)$ & 56.2 & & \\
\hline & No & $303(24.3)$ & $150(22.0)$ & 49.5 & & \\
\hline
\end{tabular}

did not use tobacco), with an AOR of $17.438,95 \%$ CI (9.139-33.276), followed by having a household member who smokes nearby (versus no household who use tobacco) [AOR 2.232, 95\% CI (1.351-3.687)], allowing smoking allowed in the home [AOR 1.710, 95\% CI (1.549-1.918)], and having a husband who smokes, but not nearby (versus a husband who did not use tobacco) [AOR 1.568, 95\% CI (1.205-2.041)]. Women who had a religious affiliation (versus those without a religion) [AOR $0.399,95 \%$ CI $(0.310-0.510)$ ] and a gravidity of 2 or more (versus the first gravidity) [AOR 0.731, 95\% CI $(0.570-0.937)]$ had a lower likelihood of SHS.

\section{Discussion}

The overall national prevalence of SHS among pregnant women in China has not yet been determined. A previous study showed that in terms of exposure to SHS at home amongst women aged 15-49 years, China had one of the highest rates $(65.1 \%)$ of the 14 low- and middleincome countries included (Bangladesh, Brazil, China,
Egypt, India, Mexico, Philippines, Poland, Russian Federation, Thailand, Turkey, Ukraine, Uruguay, and Vietnam) [30]. The majority of pregnant women fall into this age group; presumably, SHS exposure among pregnant women is not lower in China than in other countries. Compared to other domestic regional crosssectional studies, the SHS prevalence rate found in this study (northwest China, 54.6\%) was the same as that in southwest China (58.5\%) and was higher than that in the central region of China (34.26\%) and in eastern China (45.3\%) [25, 31, 32].

An analysis of the probability of exposure to SHS shows that women who had a gravidity of 2 or more had lower chances of SHS exposure [AOR 0.731, 95\% CI $(0.570,0.937)]$ compared with primigravid women. Women in their first pregnancy may lack pregnancyrelated health knowledge (e.g., lack of awareness and effective experience regarding secondhand smoke exposure prevention). In addition, under China's one-child policy, which was in place during the investigation, 
Table 4 Correlation coefficient calculated between variables $(n=1249)$

\begin{tabular}{|c|c|c|c|c|c|c|c|c|c|c|c|}
\hline $\begin{array}{l}\text { Correlation } \\
\text { Coefficient }\end{array}$ & $\begin{array}{l}\text { Home } \\
\text { smoking } \\
\text { ban }\end{array}$ & $\begin{array}{l}\text { Husband } \\
\text { tobacco } \\
\text { use }\end{array}$ & $\begin{array}{l}\text { Household } \\
\text { tobacco use } \\
\text { (except } \\
\text { husband) }\end{array}$ & age & $\begin{array}{l}\text { Gravidity } \\
\text { times }\end{array}$ & $\begin{array}{l}\text { Gestational } \\
\text { weeks }\end{array}$ & $\begin{array}{l}\text { Knowledge } \\
\text { of } \\
\text { secondhand } \\
\text { smoke harm }\end{array}$ & nationality & religion & location & $\begin{array}{l}\text { Work } \\
\text { status }\end{array}$ \\
\hline $\begin{array}{l}\text { Home } \\
\text { smoking ban }\end{array}$ & 1.000 & & & & & & & & & & \\
\hline $\begin{array}{l}\text { Husband } \\
\text { tobacco use }\end{array}$ & $0.170^{* *}$ & 1.000 & & & & & & & & & \\
\hline $\begin{array}{l}\text { Household } \\
\text { tobacco use } \\
\text { (except } \\
\text { husband) }\end{array}$ & $-0.062^{*}$ & 0.020 & 1.000 & & & & & & & & \\
\hline age & 0.046 & -0.020 & $0.083^{* *}$ & 1.000 & & & & & & & \\
\hline $\begin{array}{l}\text { Gravidity } \\
\text { times }\end{array}$ & $-0.097^{* *}$ & 0.042 & 0.016 & $-0.360^{* *}$ & 1.000 & & & & & & \\
\hline $\begin{array}{l}\text { Gestational } \\
\text { weeks }\end{array}$ & 0.047 & 0.007 & 0.004 & $0.092^{* *}$ & $-0.080^{* *}$ & 1.000 & & & & & \\
\hline $\begin{array}{l}\text { Knowledge } \\
\text { of } \\
\text { secondhand } \\
\text { smoke harm }\end{array}$ & $0.210^{* *}$ & $-0.092^{* *}$ & -0.017 & $0.087^{* *}$ & $0.127^{* *}$ & -0.018 & 1.000 & & & & \\
\hline nationality & 0.028 & -0.053 & -0.052 & $0.079^{* *}$ & $-0.058^{*}$ & $0.085^{* *}$ & $0.057^{*}$ & 1.000 & & & \\
\hline religion & -0.016 & $-0.076^{* *}$ & -0.037 & $0.068^{*}$ & 0.003 & $0.065^{*}$ & $0.121^{* *}$ & $0.806^{* *}$ & 1.000 & & \\
\hline location & $0.173^{* *}$ & -0.046 & $-0.066^{*}$ & $-0.086^{* *}$ & $-0.166^{* *}$ & 0.013 & $-0.215^{* *}$ & $0.133^{* *}$ & $-0.107^{* *}$ & 1.000 & \\
\hline Work status & $-0.074^{* *}$ & -0.009 & 0.029 & 0.054 & 0.001 & -0.037 & 0.051 & $0.074^{* *}$ & $0.058^{*}$ & -0.020 & 1.000 \\
\hline
\end{tabular}

**. Correlation is significant at the 0.01 level (2-tailed)

*. Correlation is significant at the 0.05 level (2-tailed)

women with more than one pregnancy may have experienced miscarriage. Therefore, they may be very concerned about the risk factors for pregnancy health and may have received more attention and understanding from their family systems, which may have contributed to the reduced exposure to SHS.

Similar to previous results [24], our results found that the primary source of SHS for pregnant women was husbands who smoke, followed by other household members who smoked. The difference is that we also found effects for various smoking behaviours of the husbands. The majority of the smoking husbands $(76.0 \%$, $348 / 458$ ) tried to avoid smoking near their pregnant wives in consideration of maternal and foetal health, but the risk of SHS exposure still existed [AOR 1.568, 95\% CI (1.205-2.041)]. Despite the husbands' indoor smoking behaviours, environmental tobacco smoke from the spontaneous combustion of cigarettes can also cause SHS exposure for pregnant women, along with the potential risk of third-hand smoke. These husbands are to

Table 5 Binary logistic regression predicting likelihood of pregnant women exposed to SHS $(n=1249)$

\begin{tabular}{|c|c|c|c|c|c|c|}
\hline & \multicolumn{2}{|c|}{ Unadjusted $^{\mathrm{a}}$} & \multirow[t]{2}{*}{$p$ value } & \multicolumn{2}{|c|}{ Adjusted $^{b}$} & \multirow[t]{2}{*}{$p$ value } \\
\hline & OR & $95 \% \mathrm{Cl}$ & & $\overline{O R}$ & $95 \% \mathrm{Cl}$ & \\
\hline Religion ${ }^{c}$ & 0.428 & $(0.341-0.358)$ & $<0.001$ & 0.399 & $(0.312-0.510)$ & $<0.001$ \\
\hline Gravidity times $^{d}$ & 0.819 & $(0.655-1.024)$ & 0.080 & 0.731 & $(0.570-0.937)$ & 0.013 \\
\hline Smoking allowed at home $e^{e}$ & 1.655 & $(1.517-1.829)$ & $<0.001$ & 1.710 & $(1.549-1.918)$ & 0.001 \\
\hline Husband smoke but not nearby (no tobacco use) f $^{f}$ & 1.643 & $(1.281-2.107)$ & $<0.001$ & 1.568 & $(1.205-2.041)$ & 0.001 \\
\hline Husband smoke nearby (no tobacco use) $)^{f}$ & 15.748 & $(8.376-29.608)$ & $<0.001$ & 17.438 & $(9.139-33.276)$ & $<0.001$ \\
\hline Household tobacco user (except husband) smoke nearby (no tobacco use) ${ }^{f}$ & 3.040 & $(1.916-4.823)$ & $<0.001$ & 2.232 & $(1.351-3.687)$ & 0.002 \\
\hline
\end{tabular}

Adjusted with age, gravidity times, gestational weeks, knowledge of secondhand smoke harm, religion, location, work status

${ }^{a}$ Significance $p<0.10$

${ }^{\text {b }}$ Significance $p<0.05$

'Reference category: Have a religion (versus non-religion)

${ }^{\mathrm{d}}$ Reference category: Gravidity times of 2 or more (versus the first gravidity)

'Reference category: 'Allowed' (versus 'Never allowed' and 'Not allowed, as a general rule')

fDefinition: 'nearby' is in an extent of $5 \mathrm{~m}$ 
be commended for their adjustment of their smoking behaviour. It is believed that correct guidance regarding smoking avoidance and smoking cessation can optimize the willingness of smoking husbands to make changes in the family system.

Interestingly, this study found that good knowledge of the harms of SHS had no effect on reducing the prevalence of SHS. Smoking is socially acceptable in China; $47.0 \%$ of families reported sharing cigarettes with others, and $14.17 \%$ of families reported giving cigarettes as a gift [33]. Pregnant Chinese women have always engaged in preventive behaviours by avoiding indoor SHS exposure when strangers smoke, but this behaviour was not obvious when acquaintances smoke because of concerns about disrupting family harmony and interpersonal relationships [34]. This result shows that pregnant women's SHS exposure is affected by the combined effects of family resources, and it was difficult to avoid SHS without the support of cultural and social resources, even with sufficient information and knowledge. The latest evidence suggests that tobacco exposure during the few months before conception, even with cessation in the first trimester, may also pose a risk for fetal malformation [35]. Therefore, it is necessary to change public smoking customs in China and involve people in both preconception and pregnancy health education.

Pregnant women who live in homes where smoking is allowed have a higher SHS exposure rate than those who do not [AOR 1.710, 95\% CI (1.549-1.918)]. Home smoking bans were confirmed to be an important protective factor in this study; however, it has been noted that China has the worst rates of smoking control in the home among the International Tobacco Control Policy Evaluation Project (ITC) countries, and only $20 \%$ of households do not allow smoking in the home [1]. In this study, one-third (33.5\%) of the participants reported having a smoking ban indoors; although this is higher than the rate reported by the ITC, it is still very low. China has not yet enacted legislation prohibiting smoking at home. Moreover, because women spend more time at home after pregnancy, creating a smoke-free home environment becomes seriously important. The implementation of indoor smoking bans and restrictions on tobacco advertising are the main evidence-based policy recommendations by the WHO FCTC; these strategies have proven to be among the most successful tobacco control policies and have significant policy and programmatic implications [36, 37]. In addition, the literature indicates that the involvement of women in family decision-making is a factor in the adoption of smoke-free homes [38, 39]. Home smoking bans were shown to be maintained and supported by family members out of concern for pregnant women's health. Therefore, in addition to the ongoing implementation of national tobacco control policies, encouraging and promoting the maintenance and prioritization of maternal health throughout the family is a necessary condition for the creation of smoke-free homes.

We also found some new, interesting results in this study. Religion was a protective factor that reduced the SHS exposure of pregnant women [AOR 0.399, 95\% CI $(0.312-0.510)]$. The SHS prevalence rate reported by pregnant women who had a religious affiliation $(96.9 \%$ were Islam) was much lower than those who had no religion. Xinjiang Uygur Autonomous Region is a typical multi-nationality and multi-religion region. Islam, as minority religion, is followed by the Uygur, Kazak, Hui and other more than 10 nationality groups [40]. According to the Qur'an, Muhammad once said "Verily spendthrifts are brothers of the Evil Ones; and the Evil One is to his Lord (himself) ungrateful", and "Everything that is intoxicating (narcotic, addictive) is prohibited" [41, 42]. According to Islam tenets, smoking is an extravagant behaviour that produces SHS and harm the health of oneself and others; for Muslims, it is a sin that should not be practiced. In this study, the pregnant women held religious beliefs were primarily adherents of Islam, who are opposed to smoking and are unlikely to have contact with smokers [43]. Moreover, the mosque/mullahs preach the harms of smoking/SHS and restrict tobacco use in many rituals of Muslim life [44], and religious involvement is inversely related to current smoking [45]. Adequate religious resources might objectively contribute to reducing the SHS prevalence rate of pregnant women in the Muslim community.

\section{Strengths and limitations}

This is the first published study from the perspective of a family-based open system to focus on SHS exposure status and its influencing factors among urban multinationality pregnant women in the border and minority areas in China. The results of this study may aid in the development of effective and enduring strategies to protect the health of pregnant women and foetuses.

There were several limitations of this study. First, the outcome variables relied on self-report, which can be susceptible to non-sampling errors. However, the selfreport methodology has been widely used in tobacco prevalence research and has been proven to be a valid accurate estimate when compared with biomarker findings [37, 46, 47]. Second, as gestational age increases, pregnant women usually undergo a higher frequency of foetal examinations (e.g., pregnant women in late pregnancy are required to undergo foetal heart monitoring once or twice a week). Consequently, women in middle and late pregnancy are more likely to be examined than those in early pregnancy, which may have led to sampling errors. The sample may not be a good indicator of 
SHS exposure in early pregnancy. Additionally, the study did not revise the Uighur and Kazak Language questionnaire for minority pregnant women, and data were collected with the help of trained minority nationality bilingual translators. In future studies, a questionnaire suitable for minority pregnant women can be created.

\section{Conclusions}

To sum up, this study found that the SHS prevalence rate among pregnant women was at the upper level compared to other domestic regional cross-sectional studies. Having good knowledge of the harms of SHS was not enough to reduce exposure to SHS. Although smoking husbands consciously made efforts to protect pregnant women from exposure to their secondhand smoke, the risk still existed. Therefore, our results suggest that it is very important to help smoking husbands to reduce tobacco use or to be able to correctly and effectively avoid smoking nearby. Home smoking bans were an important protective factor against SHS exposure, but such bans were in effect for only one-third of the participants. Religion, as a special resource, was an important factor in reducing SHS exposure in pregnant women who had an instinctive response (e.g., a tendency to reduce their contact with smokers) and lived in a Muslim community characterized by less SHS. The effect of religious tenets on tobacco control should be considered in the development of effective and enduring strategies for indoor smoking bans and smoking cessation in minority communities. The effect of Islam's religion tenets regarding tobacco control in this study provides perspective for further research in this field, which is especially necessary within the context of this current era of religious awakening in China.

\section{Supplementary information}

Supplementary information accompanies this paper at https://doi.org/10. 1186/s12884-020-03251-w.

Additional file 1. Supplementary questionnaire file 1.

\section{Abbreviations}

SHS: Secondhand Smoke; IAQ: Indoor Air Quality; PM2.5: Particles with a diameter less than or equal to 2.5 Micrometers; WHO FCTC: The World Health Organization Framework Convention on Tobacco Control: USD: United States Dollar; ITC: The International Tobacco Control Policy Evaluation Project

\section{Acknowledgments}

We are grateful to the medical personnel who recruited participants. We would like to thank Professor Loke Alice Yuen, Family and Community Health Division, School of Nursing, The Hong Kong Polytechnic University, Hong Kong, for her related pilot research and the initial questionnaire provided.

\section{Authors' contributions}

PF and JC conceived the original idea for the study. PF contributed to the data acquisition. JC and XL did the statistical analyses. JC wrote the manuscript. JC and XL revised the paper. All authors supplied critical revisions to the manuscript and gave final approval of the version to be published.

\section{Funding}

This work was supported by Medical Scientific Research Foundation of Guangdong Province (A2020420), Key Laboratory of Philosophy and Social Sciences of Colleges and Universities in Guangdong Province: Public Health Policy Research \&Evaluation (2015WSY0010), Public Health Service System Construction Research Foundation of Guangzhou (2018-2020), and Major Program of National Social Science Foundation of China (15ZDC037). The funding body has no effects on the manuscript writing and publication.

\section{Availability of data and materials}

The datasets used and/or analyzed during the current study are available from the corresponding author on reasonable request.

\section{Ethics approval and consent to participate}

This study was approved by the institutional ethical review board (IERB) of the First Affiliated Hospital of Shihezi University, School of Medicine of Xinjiang Autonomous Region (IERB ID No.2014-062-01). Informed consent form was obtained from all participants, permissions of participants were acquired by the research team to access the data used in this study.

\section{Consent for publication}

Not applicable.

\section{Competing interests}

The authors declare that they have no competing interests.

\section{Author details}

${ }^{1}$ School of Health Services Management, Southern Medical University, No. 1023-1063 Shatai Road, Baiyun District, Guangzhou 510515, Guangdong, China. ${ }^{2}$ School of Medicine, Shihezi University, No.221 Beisi Road, Shihezi, Xinjiang 832002, Uygur Autonomous Region, China. ${ }^{3}$ Academy of Health Policy and Management, Huazhong University of Science and Technology (Think tank), No.13 Hangkong Road, Qiaokou District, Wuhan 430030, Hubei, China. ${ }^{4}$ School of Medicine and Health Management, Tongji Medical College, Huazhong University of Science and Technology, No.13 Hangkong Road, Qiaokou District, Wuhan 430030, Hubei, China.

Received: 12 February 2018 Accepted: 14 September 2020 Published online: 21 October 2020

\section{References}

1. Organization WH, editor. Smoke-free Policies in China: Evidence of Effectiveness and Implications for Action. UC San Francisco: Center for Tobacco Control Research and Education; 2015.

2. China C. 2018 China adult tobacco survey results released; 2019.

3. Caixeta RB, Rarick EL, Shin M, Asma S, Tong V. current tobacco use and secondhand smoke exposure among women of reproductive age - 14 countries, 2008-2010. Morb Mortal Wkly Rep. 2012;61(43):877-82.

4. Lam TH, Kung IT, Wong CM, Lam WK, Kleevens JW, Saw D, Hsu C, Seneviratne S, Lam SY, Lo KK, et al. Smoking, passive smoking and histological types in lung cancer in Hong Kong Chinese women. $\mathrm{Br} J$ Cancer. 1987:56(5):673-8

5. Xu X, Liu D, Zhang Z, Sharma M, Zhao Y. Sleep Duration and Quality in Pregnant Women: A Cross-Sectional Survey in China. Int J Environ Res Public Health. 2017;14(7):817.

6. He Y, Lam TH, Jiang B, Wang J, Sai X, Fan L, Li X, Qin Y, Hu FB. Passive smoking and risk of peripheral arterial disease and ischemic stroke in Chinese women who never smoked. Circulation. 2008;118(15):1535-40.

7. Cai H, Wang C. Surviving with smog and smoke: precision interventions? Chest. 2017:152(5):925-9.

8. Pei L, Kang Y, Zhao $Y$, Cheng $Y$, Yan H. Changes in socioeconomic inequality of low birth weight and Macrosomia in Shaanxi Province of Northwest China, 2010-2013: a cross-sectional study. Medicine (Baltimore) 2016;95(5):e2471.

9. Zheng Z, Xie G, Yang T, Qin J. Congenital malformations are associated with secondhand smoke among nonsmoking women: a meta-analysis. Birth. 2019;46(2):222-33 
10. Zhang BY, Wei YS, Niu JM, Li Y, Miao ZL, Wang ZN. Risk factors for unexplained recurrent spontaneous abortion in a population from southern China. Int J Gynaecol Obstet. 2010;108(2):135-8.

11. Hu LW, Yang $M$, Chen $S$, Shah $K$, Hailegiorgis $Y$, Burgens $R$, Vaughn $M$, Huang J, Xaverius P, Paul G, et al. Effects of in utero and postnatal exposure to secondhand smoke on lung function by gender and asthma status: the seven northeastern cities (SNEC) study. Respiration. 2017;93(3):189-97.

12. Pi X, Li Z, Jin L, Liu J, Zhang Y, Zhang L, Wang L, Ren A. Secondhand smoke during the periconceptional period increases the risk for orofacial clefts in offspring. Paediatr Perinat Epidemiol. 2018;32(5):423-7.

13. Semple S, Apsley A, Azmina IT, Turner SW, Cherrie JW. Fine particulate matter concentrations in smoking households: just how much secondhand smoke do you breathe in if you live with a smoker who smokes indoors? Tob Control. 2015;24(e3):e205-11

14. Fawcett J. The family as a living open system: an emerging conceptual framework for nursing, vol. 22; 1975.

15. Pratt KJ, Skelton JA. Family functioning and childhood obesity treatment: family systems theory-informed approach. Acad Pediatr. 2018;18(6):620-7.

16. Mullins LL, Harbeck-Weber C, Olson RA, Hartman VL. Commentary: systems theory orientation and clinical practice: a survey of pediatric psychologists. J Pediatr Psychol. 1996;21(4):577-82.

17. Ling L, Chen J. Survey of passive smoking among pregnant women and smoking behavior of their husbands. Med Soc. 2018;31(3):32-4.

18. Fu C, Chen $Y$, Wang T, Edwards $N, X u$ B. Exposure to environmental tobacco smoke in Chinese new mothers decreased during pregnancy. J Clin Epidemiol. 2008;61(11):1182-6.

19. Wang $M$, Luo X, Xu S, Liu W, Ding F, Zhang X, Wang L, Liu J, Hu J, Wang W. Trends in smoking prevalence and implication for chronic diseases in China: serial national cross-sectional surveys from 2003 to 2013. Lancet Respir Med. 2019;7(1):35-45.

20. Luo KB, Mayilia H, Wang Q, Wei X, Wang ZY, Mayila M, Li FF, Lv XH. Survey on tobacco usage among adult residents in Xinjiang 2017. Chin J Health Educ. 2019;35(12):1075-80

21. Whooley MA, Boyd AL, Gardin JM, Williams DR. Religious involvement and cigarette smoking in young adults. Arch Intern Med. 2002;162(14):1604-10.

22. Nakhaee N, Divsalar K, Jadidi N. Religious involvement and cigarette smoking among Iranian University students. Int J Psychiatry Med. 2009; 39(2):189-98.

23. Panganiban-Corales AT, Medina MJ. Family resources study: part 1: family resources, family function and caregiver strain in childhood cancer. Asia Pac Fam Med. 2011;10(1):14.

24. Di J, Wang L, Xu G, Chen X, Hu D. Analysis on passive smoking status of pregnant women. Matern Child Health Care China. 2010;10:1323-6.

25. Huang X, Wei M, Zhu H, Wang J, Zhou R, Yu F. Survey on the influencing factors for passive smoking among women at early stages of pregnancy in Shanghai City. Mod Prev Med. 2014;20:3696-9.

26. Wannian L. Introduction to general practice: people's medical publishing house; 2006.

27. Roach AJ, Frazier LP, Bowden SR. The marital satisfaction scale: development of a measure for intervention research. J Marriage Fam. 1981;43(3):537-46.

28. CDC: Second-hand smoke health hazards. 2012.

29. Xiao L, Yang Y, Li Q, Wang CX, Yang GH. Population-based survey of secondhand smoke exposure in China. Biomed Environ Sci. 2010;23(6): 430-6.

30. Centers for Disease Control and Prevention. Current tobacco use and secondhand smoke exposure among women of reproductive age--14 countries, 2008-2010. Morb Mortal Wkly Rep. 2012;61(43):877-82.

31. Xiao X, Qin Q, Xu Q, Yu M, Cao H, Li X. Investigation and analysis on passive smoking among pregnant women during perinatal period. Matern Child Health Care China. 2016;13:2709-11.

32. Liang Z, Wang Z, Yang S, Du Y, Shen M. Study on the correlation between maternal passive smoking during pregnancy and depression. Matern Child Health Care China. 2015;1:23-6.

33. Xu Y, Xu S, Wu Q, Guo Y. Association between secondhand smoke exposure at home and cigarette gifting and sharing in Zhejiang, China: a repeat cross-sectional study. BMJ Open. 2016;6(3):e10058.

34. Xu X, Rao Y, Abdullah AS, Sharma M, Guo JJ, Zhao Y. Preventive behaviours in avoiding indoor secondhand smoke exposure among pregnant women in China. Tob Control. 2017;26(4):483-4.

35. Perry MF, Mulcahy $H$, DeFranco EA. Influence of periconception smoking behavior on birth defect risk. Am J Obstet Gynecol. 2019;220(6):588.e1-7.
36. Organization WH: WHO report on the global tobacco epidemic, 2013. Enforcing bans on tobacco advertising, promotion and sponsorship 2013.

37. Policies IWGO. Methods for evaluating tobacco control policies. Methods Evaluating Tob Control Policies. 2008;12(2):133-9.

38. Berg CJ, Zheng P, Kegler MC. Perceived benefits of smoke-free homes, the process of establishing them, and enforcement challenges in Shanghai, China: a qualitative study. BMC Public Health. 2015;15:89.

39. Burdette LK, Rowe GC, Johansen L, Kerkvliet JL, Nagelhout E, Lewis $K$, Fahrenwald NL. A statewide assessment of smoke-free policy in multiunit housing settings. Nicotine Tob Res. 2014;16(12):1593-8.

40. Ma Z. An Analysis of the Development of Muslim Population in China. J Guizhou Univ (Social Science). 2014;03:98-106

41. Muhammad. the Koran. Beijing: Chinese Social Science Press; 2003.

42. Abdul MS. An analysis of the teachings of Islam. Beijing: Religion and Culture Publishing House; 2013.

43. Zhu Y. Religious taboos in contemporary China. Beijing: Ethnic Press of China; 2001

44. Bai X, Chen JY, Fang Z, Zhang XY, Wang F, Pan ZQ, Fang PQ. Motivations, challenges and coping strategies for smoking cessation: based on multiethnic pregnant couples in far western China. J Huazhong Univ Sci Technolog Med Sci. 2017;37(3):439-45.

45. Wang Z, Koenig HG, Al SS. Religious involvement and tobacco use in mainland China: a preliminary study. BMC Public Health. 2015;15:155.

46. Petersen AB, Thompson LM, Dadi GB, Tolcha A, Cataldo JK. Factors associated with secondhand tobacco smoke in the home: an exploratory cross-sectional study among women in Aleta Wondo, Ethiopia. BMC Public Health. 2016;16:910

47. Florescu A, Ferrence R, Einarson T, Selby P, Soldin O, Koren G. Methods for quantification of exposure to cigarette smoking and environmental tobacco smoke: focus on developmental toxicology. Ther Drug Monit. 2009:31(1):14-30.

\section{Publisher's Note}

Springer Nature remains neutral with regard to jurisdictional claims in published maps and institutional affiliations.

Ready to submit your research? Choose BMC and benefit from:

- fast, convenient online submission

- thorough peer review by experienced researchers in your field

- rapid publication on acceptance

- support for research data, including large and complex data types

- gold Open Access which fosters wider collaboration and increased citations

- maximum visibility for your research: over $100 \mathrm{M}$ website views per year

At $\mathrm{BMC}$, research is always in progress.

Learn more biomedcentral.com/submissions 